\title{
Molecular Dynamics Simulations of Electrolyte Solutions at the (100) Goethite Surface
}

\author{
Sebastien Kerisit ${ }^{1}$, Eugene S. Ilton ${ }^{1}$, Stephen C. Parker ${ }^{2}$
}

${ }^{1}$ Chemical Sciences Division, Pacific Northwest National Laboratory, Richland WA 99352 USA

${ }^{2}$ Department of Chemistry, University of Bath, Claverton Down, Bath BA2 7AY, UK

\section{SUPPORTING INFORMATION}

Table I. Potential parameters used in this work.

\begin{tabular}{cccc}
\hline & \multicolumn{3}{c}{ Charges and core-shell spring constants $^{\mathbf{a}}$} \\
Ion & Core $(e)$ & Shell $(e)$ & $k\left(\mathrm{eV} . \AA^{-2}\right)$ \\
\hline Iron $(\mathrm{Fe})$ & 3.000 & - & - \\
Cesium $(\mathrm{Cs})$ & 1.000 & - & - \\
Sodium $(\mathrm{Na})$ & 1.000 & - & - \\
Hydrogen $(\mathrm{H})$ & 0.400 & - & - \\
Fluoride $(\mathrm{F})$ & 1.380 & -2.380 & 101.20 \\
Chloride $(\mathrm{Cl})$ & 1.485 & -2.485 & 29.38 \\
Lattice $\mathrm{O}\left(\mathrm{O}_{\mathrm{L}}\right)$ & 0.210 & -2.210 & 27.40 \\
Hydroxyl O $\left(\mathrm{O}_{\mathrm{H}}\right)$ & 0.900 & -2.300 & 74.92 \\
Water $\mathrm{O}\left(\mathrm{O}_{\mathrm{W}}\right)$ & 1.250 & -2.050 & 209.45 \\
& Buckingham potential parameters & \\
Ion pair $(i j)$ & $A_{i j}(e V)$ & $\rho_{i j}(\AA)$ & $C_{i j}\left(\mathrm{eV} . A^{6}\right)$ \\
$\mathrm{Fe}-\mathrm{F}$ & 640.00 & 0.3299 & 0.00 \\
$\mathrm{Fe}-\mathrm{Cl}$ & 738.40 & 0.4161 & 0.00 \\
$\mathrm{Fe}-\mathrm{O}_{\mathrm{L}}$ & 1102.40 & 0.3299 & 0.00 \\
$\mathrm{Fe}-\mathrm{O}_{\mathrm{H}}$ & 771.40 & 0.3299 & 0.00 \\
$\mathrm{Fe}-\mathrm{O}_{\mathrm{w}}$ & 440.80 & 0.3372 & 0.00 \\
$\mathrm{Cs}-\mathrm{F}$ & 1050.00 & 0.3420 & 0.00 \\
$\mathrm{Cs}-\mathrm{Cl}$ & 2900.00 & 0.3420 & 0.00 \\
$\mathrm{Cs}-\mathrm{O}_{\mathrm{L}}$ & 2500.00 & 0.3420 & 0.00 \\
$\mathrm{Cs}-\mathrm{O}_{\mathrm{H}}$ & 1750.00 & 0.3420 & 0.00 \\
$\mathrm{Cs}-\mathrm{O}_{\mathrm{w}}$ & 1000.00 & 0.3420 & 0.00 \\
$\mathrm{Na}-\mathrm{Cl}$ & 2314.70 & 0.2903 & 0.00 \\
$\mathrm{Na}-\mathrm{O}_{\mathrm{L}}$ & 1226.84 & 0.3065 & 0.00 \\
$\mathrm{Na}-\mathrm{O}_{\mathrm{H}}$ & 858.79 & 0.3065 & 0.00 \\
$\mathrm{Na}-\mathrm{O}_{\mathrm{w}}$ & 2334.72 & 0.2387 & 0.00 \\
$\mathrm{H}-\mathrm{O}_{\mathrm{L}}$ & 396.27 & 0.2500 & \\
$\mathrm{H}-\mathrm{O}_{\mathrm{H}}$ & 311.97 & 0.2500 & \\
\hline
\end{tabular}


Table I. (cont.)

\begin{tabular}{|c|c|c|c|c|}
\hline \multicolumn{5}{|c|}{ Buckingham potential parameters $^{\mathrm{b}}$} \\
\hline Ion pair (ij) & $A_{i j}(\mathrm{eV})$ & $\rho_{i j}(\AA)$ & \multicolumn{2}{|r|}{$C_{i j}\left(e V . A^{6}\right)$} \\
\hline $\mathrm{F}-\mathrm{O}_{\mathrm{L}}$ & 79785221 & 0.1201 & \multicolumn{2}{|r|}{26.79} \\
\hline $\mathrm{F}-\mathrm{O}_{\mathrm{H}}$ & 79785221 & 0.1201 & \multicolumn{2}{|r|}{26.79} \\
\hline F-F & 1127.7 & 0.2753 & \multicolumn{2}{|r|}{15.83} \\
\hline $\mathrm{Cl}-\mathrm{O}_{\mathrm{L}}$ & 1272.25 & 0.2352 & \multicolumn{2}{|r|}{28.46} \\
\hline $\mathrm{Cl}-\mathrm{O}_{\mathrm{H}}$ & 1272.25 & 0.2352 & \multicolumn{2}{|r|}{14.23} \\
\hline $\mathrm{Cl}-\mathrm{Cl}$ & 1227.20 & 0.3214 & \multicolumn{2}{|r|}{29.06} \\
\hline $\mathrm{O}_{\mathrm{L}}-\mathrm{O}_{\mathrm{L}}$ & 22764.00 & 0.1490 & \multicolumn{2}{|r|}{27.88} \\
\hline $\mathrm{O}_{\mathrm{L}}-\mathrm{O}_{\mathrm{H}}$ & 22764.00 & 0.1490 & \multicolumn{2}{|r|}{13.94} \\
\hline $\mathrm{O}_{\mathrm{L}}-\mathrm{O}_{\mathrm{W}}$ & 22764.00 & 0.1490 & \multicolumn{2}{|r|}{15.46} \\
\hline $\mathrm{O}_{\mathrm{H}}-\mathrm{O}_{\mathrm{H}}$ & 22764.00 & 0.1490 & \multicolumn{2}{|r|}{6.97} \\
\hline $\mathrm{O}_{\mathrm{H}}-\mathrm{O}_{\mathrm{W}}$ & 22764.00 & 0.1490 & \multicolumn{2}{|r|}{15.46} \\
\hline \multicolumn{5}{|c|}{ Lennard-Jones potential parameters ${ }^{\mathrm{c}}$} \\
\hline Ion pair (ij) & $A_{i j}\left(e V . A^{n}\right)$ & $B_{i j}\left(e V . A^{m}\right)$ & $n$ & $m$ \\
\hline H-F & 0.71 & 0.65 & 9 & 6 \\
\hline $\mathrm{H}-\mathrm{Cl}$ & 147.01 & 16.36 & 9 & 6 \\
\hline $\mathrm{H}-\mathrm{O}_{\mathrm{W}}$ & 24.00 & 6.00 & 9 & 6 \\
\hline $\mathrm{F}-\mathrm{O}_{\mathrm{W}}$ & 32796.02 & 76.83 & 12 & 6 \\
\hline $\mathrm{Cl}-\mathrm{O}_{\mathrm{w}}$ & 141959.17 & 159.85 & 12 & 6 \\
\hline $\mathrm{Ow}-\mathrm{Ow}$ & 39344.98 & 42.15 & 12 & 6 \\
\hline \multicolumn{5}{|c|}{ Morse potential parameters $^{\mathrm{d}}$} \\
\hline Ion pair (ij) & $D_{i j}(e V)$ & $\alpha_{i j}\left(\AA^{-1}\right)$ & $r_{0}(\AA)$ & Coul. Sub. (\%) \\
\hline $\mathrm{O}_{\mathrm{H}}-\mathrm{H}$ & 7.0525 & 3.1749 & 0.9258 & 0 \\
\hline $\mathrm{Ow}-\mathrm{H}$ & 6.2037 & 2.2200 & 0.9237 & 50 \\
\hline $\mathrm{H}-\mathrm{H}$ & 0.0000 & 2.8405 & 1.5000 & 50 \\
\hline \multicolumn{5}{|c|}{ Three-body potential parameters ${ }^{\mathrm{e}}$} \\
\hline Ions (ijk) & \multicolumn{2}{|c|}{$k_{i j k}\left(e V \cdot r a d^{-2}\right)$} & \multicolumn{2}{|r|}{$\theta_{0}$} \\
\hline $\mathrm{H}-\mathrm{Ow}-\mathrm{H}$ & \multicolumn{2}{|c|}{4.1998} & \multicolumn{2}{|r|}{108.69} \\
\hline
\end{tabular}

(a) Spring constant potential form: $\mathrm{V}=\mathrm{k} \cdot \mathrm{r}_{\mathrm{c}-\mathrm{s}}{ }^{2}$

(b) Buckingham potential form: $\mathrm{V}_{\mathrm{ij}}=\mathrm{A}_{\mathrm{ij}} \exp \left(-\mathrm{r}_{\mathrm{ij}} / \rho_{\mathrm{ij}}\right)-\mathrm{C}_{\mathrm{ij}} \mathrm{r}_{\mathrm{ij}}{ }^{-6}$

(c) Lennard-Jones potential form: $\mathrm{V}_{\mathrm{ij}}=\mathrm{A}_{\mathrm{ijj}} \mathrm{r}_{\mathrm{ij}}{ }^{-\mathrm{n}}-\mathrm{B}_{\mathrm{ij}} \mathrm{r}_{\mathrm{ij}}{ }^{-\mathrm{m}}$

(d) Morse potential form: $V_{\mathrm{ij}}=\mathrm{D}_{\mathrm{ij}}\left(1-\exp \left[-\alpha_{\mathrm{ij}}\left(\mathrm{r}_{\mathrm{ij}}-\mathrm{r}_{0}\right)\right]^{2}\right)-\mathrm{D}_{\mathrm{ij}}$

(e) Three-body potential form: $\mathrm{V}_{\mathrm{ijk}}=0.5 \cdot \mathrm{k}_{\mathrm{ijk}}\left(\theta_{\mathrm{ijk}}-\theta_{0}\right)^{2}$ 


\section{FLUORIDE ION-WATER POTENTIAL FITTING}

Table II. Comparison of the structure of small fluoride-water gas-phase clusters obtained in this work with published electronic structure calculations.

\begin{tabular}{lcccc}
\hline Source & $R\left(\mathrm{~F}-\mathrm{H}_{1}\right), \AA$ & $R(\mathrm{~F}-\mathrm{O}), \AA$ & $\Phi\left(\mathrm{F}-\mathrm{H}_{1}-\mathrm{O}\right), \mathrm{deg}$ & $\begin{array}{c}\mathrm{E}_{\mathrm{BINDING}} \\
\mathrm{eV}\end{array}$ \\
\hline This work & 1.56 & $\mathbf{F}\left(\mathbf{H}_{2} \mathbf{O}\right)^{-}\left(\mathbf{C}_{\mathbf{s}}\right)$ & & \\
Reference a & $1.365-1.511$ & 2.58 & 173.8 & 0.962 \\
Reference b & $1.386-1.494$ & $2.436-2.494$ & $174.8-177.6$ & $1.02-1.23$ \\
& & $\mathbf{F}\left(\mathbf{H}_{2} \mathbf{O}\right)_{2}{ }^{-}\left(\mathbf{C}_{2}\right)$ & - & 1.062 \\
This work & $1.57,1.62$ & $2.59,2.61$ & 0.970 \\
Reference a & $1.515-1.597$ & $2.497-2.572$ & $170.4,174.8$ & $0.833-0.932$ \\
Reference b & $1.520-1.543$ & $2.526-2.569$ & $172.9-173.3$ & 0.967 \\
& & $\mathbf{F}\left(\mathbf{H}_{2} \mathbf{O}\right)_{3}{ }^{-}\left(\mathbf{C}_{3}\right)$ & - & 0.978 \\
This work & $1.63(\times 3)$ & $2.62(\times 3)$ & $170.9(\times 3)$ & $0.698-0.837$ \\
Reference a & $1.629-1.672$ & $2.610-2.632$ & - & 0.896 \\
Reference b & $1.592-1.693$ & $2.582-2.642$ & - & 0.957 \\
This work & $1.64(\times 2) 1.65(\times 2)$ & $2.63(\times 2) 2.64(\times 2)$ & $171.6(\times 3) 171.2(\times 3)$ & $0.85 \pm 0.05$ \\
Reference c & $1.710(\times 4)$ & $2.670(\times 4)$ & - & \\
\hline
\end{tabular}

(a) Xantheas, S.S.; Dunning Jr., T.H. J. Phys. Chem. 1994, 98, 13489. Level of theory: Hartree-Fock (HF), second-order perturbation theory (MP2), and fourth-order perturbation theory (MP4) with aug-cc-pVDZ and aug-cc-pVTZ basis sets.

(b) Baik, J.; Kim, J.; Majumdar, D.; Kim, K.S. J. Chem. Phys. 1999, 110, 9116. Level of theory: HF with 6$31+\mathrm{G}^{*}$ and Mclean-Chandler VDZ basis sets, MP2 with $6-311++\mathrm{G}^{* *}$ basis set, and density functional theory (DFT) with BLYP exchange-correlation potential and 6-311++G** basis set.

(c) Kim, J.; Lee, H.M.; Suh, S.B.; Majumdar, D.; Kim, K.S. J. Chem. Phys. 2000, 113, 5259. Level of theory: MP2 with 6-311++G** basis set. 
Table III. Comparison of the structure of the first hydration shell of fluoride ions in aqueous solution obtained in this work with experimental and theoretical data published in the literature.

\begin{tabular}{lccc}
\hline Source & $R(\mathrm{~F}-\mathrm{H}), \AA$ & $R(\mathrm{~F}-\mathrm{O}), \AA$ & $n_{\mathrm{FH}}$ \\
\hline This work & 1.68 & 2.63 & 7.8 \\
Reference a (QM/MM) & 1.74 & 2.68 & 4.6 \\
Reference b (calculations) & $1.30-1.73$ & $2.60-2.67$ & $4.0-6.8$ \\
Reference b (experiments) & - & $2.62-2.92$ & $4.0-6.0$ \\
\hline
\end{tabular}

(a) Tongraar, A.; Rode, B.M. Phys. Chem. Chem. Phys. 2003, 5, 357. Level of theory: quantum mechanics/ molecular mechanics $(\mathrm{QM} / \mathrm{MM})$ with $\mathrm{QM}$ part treated at the HF level with the $\mathrm{D} 95 \mathrm{~V}+$ and $6-31+\mathrm{G}$ basis sets for fluoride ions and water, respectively.

(b) Ohtaki, H.; Radnai, T. Chem. Rev. 1993, 93, 1157. Review of experimental and theoretical data on hydration of ions. 


\section{CESIUM ION-WATER POTENTIAL FITTING}

Table IV. Comparison of the energy $(\mathrm{kcal} / \mathrm{mol})$ of $\mathrm{Cs}-\mathrm{H}_{2} \mathrm{O}$ gas-phase clusters obtained in this work with published electronic structure calculations.

\begin{tabular}{cccccc}
\hline$N\left(\mathrm{H}_{2} \mathrm{O}\right)$ & This work & $\mathrm{HF}^{\mathrm{a}}$ & $\mathrm{MP}^{\mathrm{a}}$ & ${\mathrm{B} 3 L Y \mathrm{~L}^{\mathrm{a}}}^{\mathrm{a}}$ & $\mathrm{BP}^{\mathrm{a}}$ \\
\hline 1 & -10.3 & -14.0 & -14.4 & -14.5 & -14.0 \\
2 & -20.2 & -26.9 & -27.8 & -28.0 & -27.2 \\
3 & -29.2 & -38.5 & -39.9 & -40.5 & -39.4 \\
4 & -37.6 & -48.6 & -50.6 & -51.3 & -50.1 \\
6 & -52.0 & -63.6 & -66.8 & -67.7 & -66.6 \\
8 & -78.1 & -71.4 & -76.3 & -76.3 & -75.2 \\
\hline
\end{tabular}

(a) Schwenk, C.F.; Hofer, T.S.; Rode, B.M. J. Phys. Chem. A 2004, 108, 1509.

Table V. Comparison of the $\mathrm{Cs}-\mathrm{O}\left(\mathrm{H}_{2} \mathrm{O}\right)$ distance $(\AA)$ in $\mathrm{Cs}^{-} \mathrm{H}_{2} \mathrm{O}$ gas-phase clusters obtained in this work with published electronic structure calculations.

\begin{tabular}{cccccc}
\hline$N\left(\mathrm{H}_{2} \mathrm{O}\right)$ & This work & $\mathrm{HF}^{\mathrm{a}}$ & $\mathrm{MP2}^{\mathrm{a}}$ & $\mathrm{B3LYP}^{\mathrm{a}}$ & $\mathrm{BP}^{\mathrm{a}}$ \\
\hline 1 & 3.04 & 3.13 & 3.12 & 3.08 & 3.11 \\
2 & 3.05 & 3.16 & 3.15 & 3.12 & 3.14 \\
3 & 3.07 & 3.17 & 3.17 & 3.13 & 3.15 \\
4 & 3.09 & 3.21 & 3.20 & 3.16 & 3.18 \\
6 & 3.13 & 3.29 & 3.26 & 3.23 & 3.25 \\
8 & 3.29 & 3.37 & 3.34 & 3.32 & 3.35 \\
\hline
\end{tabular}

(a) Schwenk, C.F.; Hofer, T.S.; Rode, B.M. J. Phys. Chem. A 2004, 108, 1509. 
Table VI. Comparison of the structure and dynamics of the first hydration shell of cesium ions in aqueous solution obtained in this work with experimental and theoretical data published in the literature.

\begin{tabular}{cccccc}
\hline Source & $R\left(1^{\text {st }}\right.$ max. $), \AA$ & $R\left(1^{\text {st }}\right.$ min. $), \AA$ & $n_{\text {CsO }}$ & $\tau, \mathrm{ps}$ & $\mathrm{D}, 10^{-9} \mathrm{~m}^{2} / \mathrm{s}$ \\
\hline This work & 3.18 & 4.1 & $10.5 \pm 0.1$ & $5.3 \pm 0.5$ & $2.5 \pm 0.5$ \\
Reference a & $2.95-3.21$ & - & $6-8$ & $\leq 100$ & - \\
Reference b & 3.0 (fixed in fit) & - & 7.9 & - & - \\
Reference c & $3.20-3.30$ & $4.1-4.2$ & $7.8-9.1$ & $1.5-2.2$ & - \\
Reference d & 3.25 & 4.20 & $10.0 \pm 0.3$ & $11.1 \pm 3.2$ & $0.83 \pm 0.12$ \\
Reference e & 3.05 & 3.85 & 9.6 & 9.5 & $2.00 \pm 0.35$ \\
\hline
\end{tabular}

(a) Ohtaki, H.; Radnai, T. Chem. Rev. 1993, 93, 1157. Review of experimental and theoretical data on hydration of ions.

(b) Ramos, S.; Neilson, G.W.; Barnes, A.C. J. Chem. Phys. 2005, 123, 214501. Experimental technique: anomalous x-ray diffraction.

(c) Schwenk, C.F.; Hofer, T.S.; Rode, B.M. J. Phys. Chem. A 2004, 108, 1509. Level of theory: QM/MM with QM part treated at the HF, B3LYP or BP86 level with DZP basis set for water and LANL2DZ effective core potential basis set for cesium.

(d) Lee, S.H.; Rasaiah, J.C. J. Chem. Phys. 1994, 101, 6964. Potential model: molecular dynamics (MD) simulation using TIP4P water model and TIPS potential for cesium-water interaction.

(e) Lee, S.H.; Rasaiah, J.C. J. Phys. Chem. 1996, 100, 1420. Potential model: MD simulation using SPC/E water model and with refitted cesium-water potential parameters. 


\section{CESIUM-FLUORIDE POTENTIAL FITTING}

Table VII. Comparison of CsF physical constants obtained in this work with published experimental data.

\begin{tabular}{lllc}
\hline Constant & Calc. & Exp. & Reference $^{\text {a }}$ \\
\hline Lattice constant $(\AA)$ & 6.01 & 6.03 & Posnjak and Wyckoff $^{\mathrm{a}}$ \\
Static dielectric constant & 4.60 & 7.90 & Hardy and Caro $^{\mathrm{b}}$ \\
Optic dielectric constant & 1.19 & 2.16 & Tessman et al. $^{\mathrm{c}}$ \\
Elastic constant $\mathrm{C}_{11}\left(10^{11} \mathrm{dyn} / \mathrm{cm}^{2}\right)$ & 3.67 & 4.56 & Bührer $^{\mathrm{d}}$ \\
Elastic constant $\mathrm{C}_{12}\left(10^{11} \mathrm{dyn} / \mathrm{cm}^{2}\right)$ & 0.99 & 1.15 & Bührer $^{\mathrm{d}}$ \\
Elastic constant $\mathrm{C}_{14}\left(10^{11} \mathrm{dyn} / \mathrm{cm}^{2}\right)$ & 0.99 & 0.80 & Bührer $^{\mathrm{d}}$ \\
\hline
\end{tabular}

(a) Posnjak, E.; Wyckoff, R.W.G. Journal of the Washington Academy of Sciences 1922, 12, 248.

(b) Hardy, J.R.; Kara, A.M. Phys. Rev. 1968, 168, 1054.

(c) Tessman, J.R.; Khan, A.H.; Schockley, W. Phys. Rev. 1953, 92, 890.

(d) Bührer, W. J. Phys. C 1973, 6, 2931. 


\section{CESIUM-CHLORIDE POTENTIAL FITTING}

Table VIII. Comparison of $\mathrm{CsCl}$ physical constants obtained in this work with published experimental data.

\begin{tabular}{lllc}
\hline Constant & Calc. & Exp. & Reference \\
\hline Lattice constant $(\AA)$ & 4.12 & 4.12 & Davey and Wick $^{\mathrm{a}}$ \\
Static dielectric constant & 5.74 & 7.20 & Stoneham and Dhote $^{\mathrm{b}}$ \\
Optic dielectric constant & 1.62 & 2.60 & Mei et al. $^{\mathrm{c}}$ \\
Elastic constant $\mathrm{C}_{11}\left(10^{11} \mathrm{dyn} / \mathrm{cm}^{2}\right)$ & 3.84 & 3.68 & Chang et al. $^{\mathrm{d}}$ \\
Elastic constant $\mathrm{C}_{12}\left(10^{11} \mathrm{dyn} / \mathrm{cm}^{2}\right)$ & 0.40 & 0.89 & Chang et al. $^{\mathrm{d}}$ \\
Elastic constant $\mathrm{C}_{14}\left(10^{11} \mathrm{dyn} / \mathrm{cm}^{2}\right)$ & 0.40 & 0.82 & Chang et al. $^{\mathrm{d}}$ \\
\hline
\end{tabular}

(a) Davey, W.P.; Wick, F.G. Phys. Rev. 1921, 17, 403.

(b) Stoneham, M.; Dhote, J. Crystal Data Compilation (http://www.oxmat.co.uk/Crysdata/homepage.htm)

(c) Mei, W.N.; Boyer, L.L.; Mehl, M.J.; Ossowski, M.M.; Stokes, H.T. Phys. Rev. B., 2000, 61, 11425.

(d) Chang, Z.P.; Barsch, G.R.; Miller, D.L. Phys. Stat. Sol. 1967, 23, 577. 


\section{IRON-FLUORIDE POTENTIAL FITTING}

Table IX. Comparison of $\mathrm{FeF}_{3}$ lattice constants obtained in this work with published experimental data.

\begin{tabular}{lccc}
\hline Constant & Calc. & Exp. & Reference \\
\hline$a(\AA)$ & 5.13 & 5.21 & Sowa and Ahsbahs $^{\mathrm{a}}$ \\
$c(\AA)$ & 13.51 & 13.32 & Sowa and Ahsbahs $^{\mathrm{a}}$ \\
\hline
\end{tabular}

(e) Sowa, H.; Ahsbahs, H. Acta Crystallogr.B 1998, 54, 578. 


\section{MOLECULAR DYNAMICS SIMULATIONS}

Figure I. Projection on the normal to the surface of the trajectory of one randomly selected sodium (black), chloride (dark grey), and water oxygen (light grey) ion in the simulation of $\mathrm{NaCl}$ electrolyte solution at the (100) goethite surface. The thick horizontal lines indicate the two surfaces of the mineral slabs.

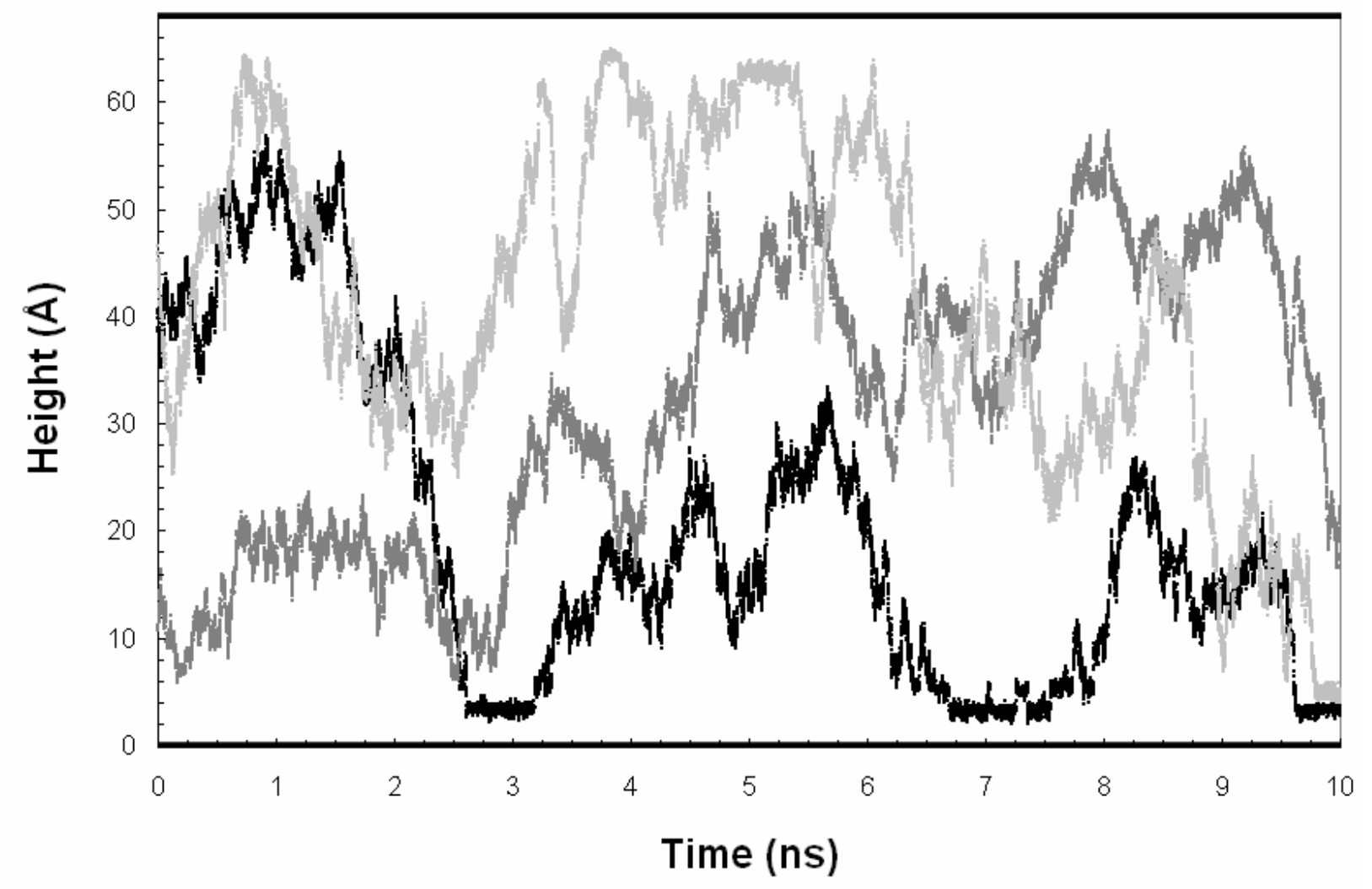


Table X. Comparison of experimental and calculated enthalpies of hydration $(\mathrm{kJ} / \mathrm{mol})$ of the four electrolyte ions considered in this work. Calculated values were obtained from MD simulations of a single ion in a periodic box containing 255 water molecules. The simulations were run in the NPT ensemble at $300 \mathrm{~K}$ and zero-applied pressure for $1 \mathrm{~ns}$. Uncertainties were calculated as the standard deviation of the mean when the trajectories were divided into five independent blocks.

\begin{tabular}{ccc}
\hline Species & Experimental & Calculated \\
\hline $\mathrm{F}^{-}$ & -510 & $-676 \pm 14$ \\
$\mathrm{Cl}^{-}$ & -365 & $-533 \pm 8$ \\
$\mathrm{Na}^{+}$ & -415 & $-366 \pm 10$ \\
$\mathrm{Cs}^{+}$ & -280 & $-156 \pm 11$ \\
\hline
\end{tabular}


Figure II. Comparison of the ion-oxygen RDFs obtained when the ions are in bulk water and when adsorbed at the interface. The interface RDF is divided between oxygen atoms of the different hydration layers and those of surface hydroxyls. The $\mathrm{RDF}$ are obtained from the simulations of $\mathrm{NaCl}$ for sodium and chloride ions, $\mathrm{CsCl}$ for oxygen and cesium, and $\mathrm{CsF}$ for fluoride ions.
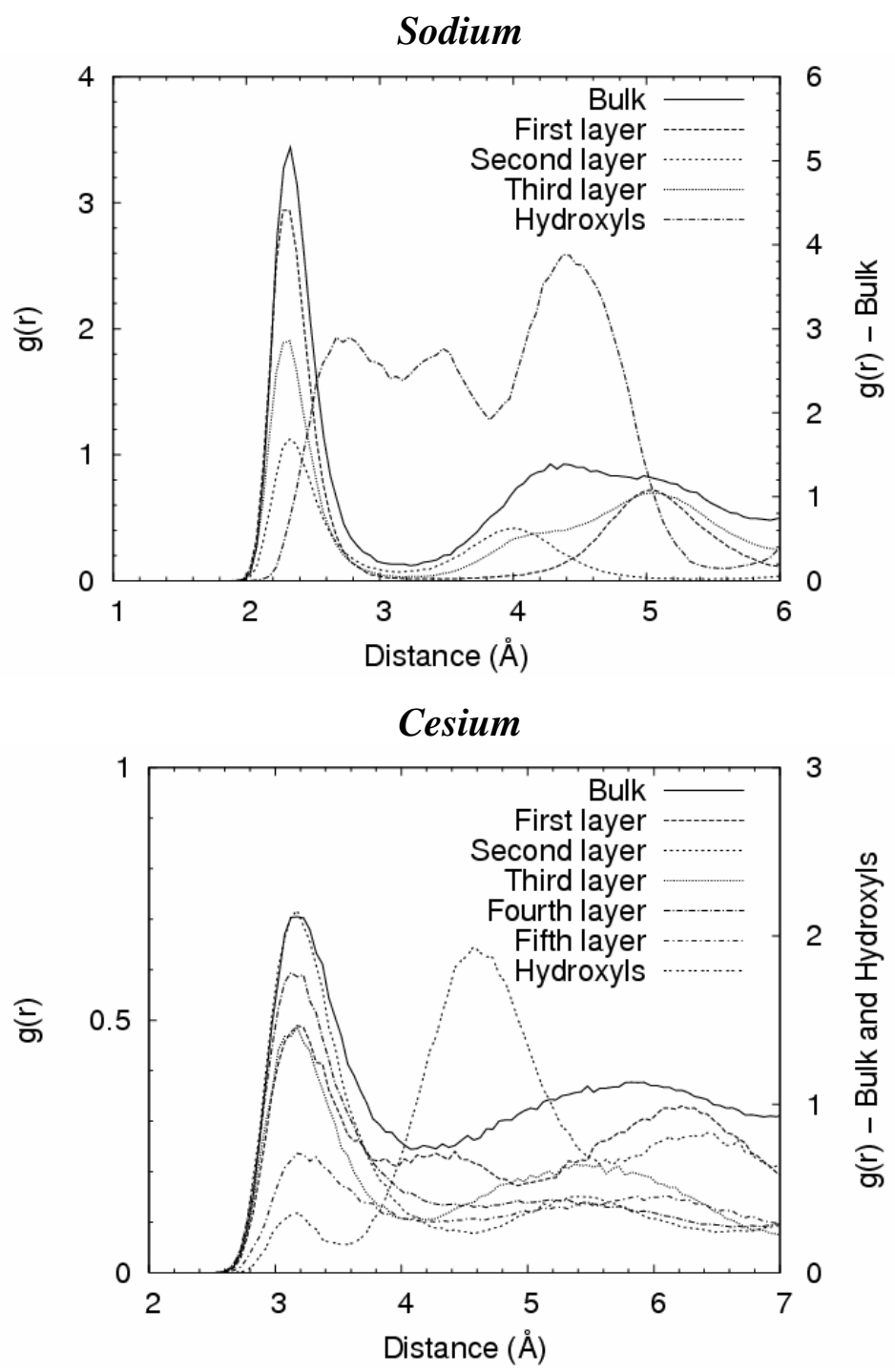


\section{Chloride}

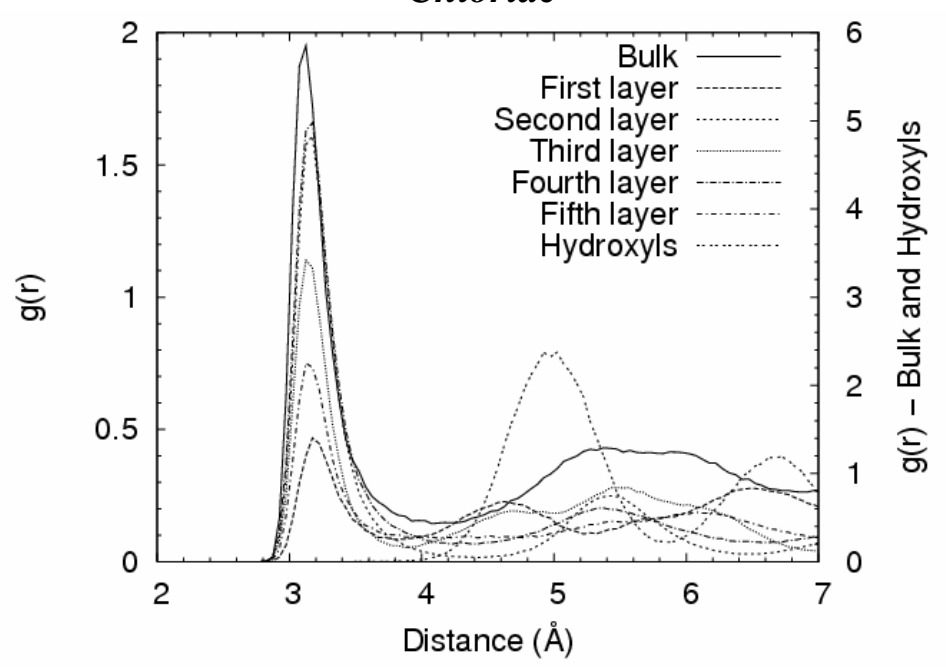

Fluoride

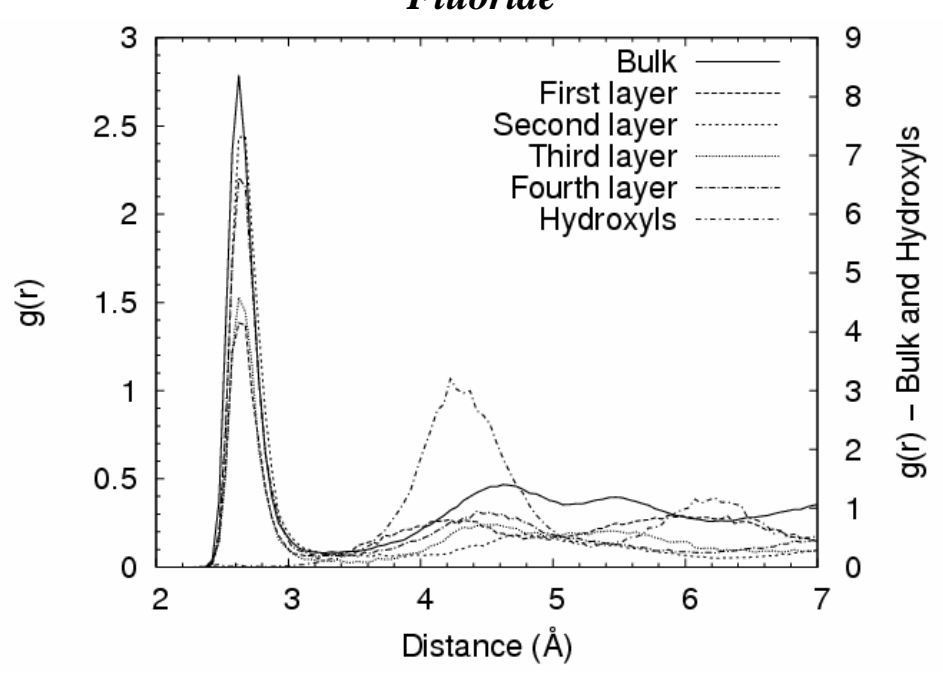

Water Oxygen

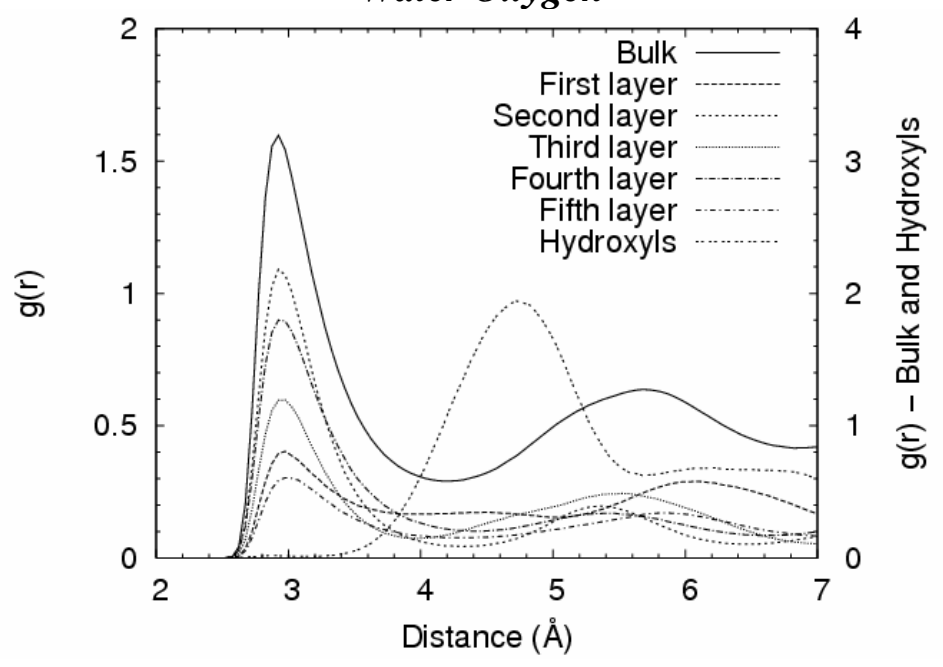


Figure III. Fluoride-fluoride and cesium-cesium potential of mean force (PMF).

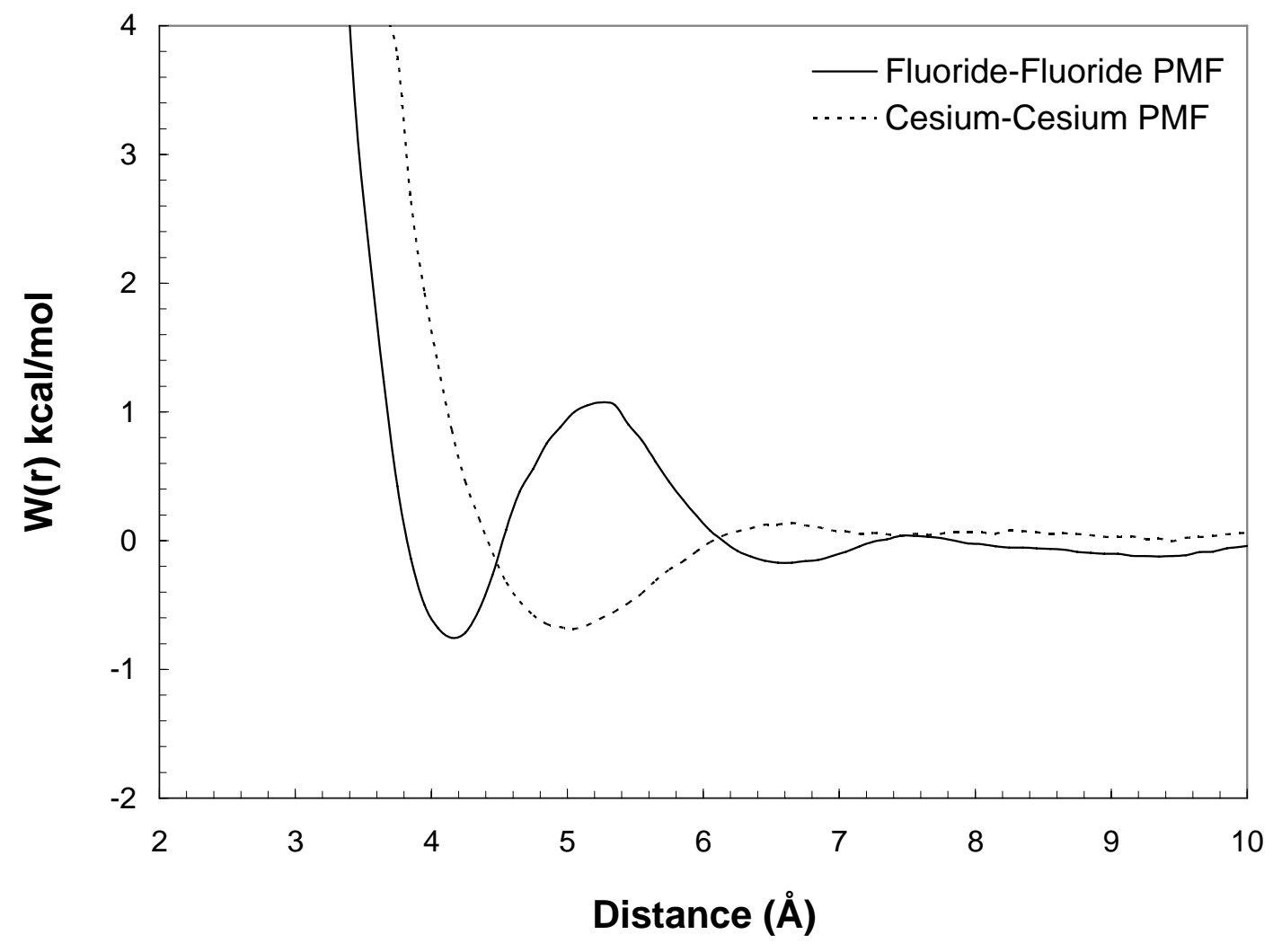

